\title{
Biological Studies on Dipha aphidivora Meyrick (Pyralidae: Lepidoptera): A Potential Predator of Coconut Mealybugs in the Philippines
}

\author{
J.C. Orense ${ }^{1}$, E.C. Bauzon², M.L.R. Imperial ${ }^{3}$ and E.P. Pacumbaba ${ }^{4}$
}

\begin{abstract}
Dipha (Conobathra) aphidivora Meyrick (Pyralidae: Lepidoptera) is recorded for the first time as a predator of coconut mealybug, Sangicoccus sp. (Eriococcidae: Homoptera)) in the Philippines. Some aspects of its biology and ecology were studied to determine its suitability as a biological control agent against Sangicoccus sp.

The life history of $D$. aphidivora was investigated following the establishment of a rearing procedure. The incubation period of the egg was $4.64 \pm 0.70$ days. The four larval instars larva were completed in 5.52 $\pm 0.92,3.40 \pm 0.91,2.83 \pm 0.72$ and 3.40 \pm 1.04 days, respectively. Adults emerged from pupae after $7.68 \pm 0.99$ days. Adult longevity was $6.83 \pm 2.30$ days. The life cycle of $D$. aphidivora lasted for $32.42 \pm 3.63$ days.

Voracity tests showed that the four larval instars of the predator consumed an average of 150 mealybugs.
\end{abstract}

Keywords: Dipha aphidivora, Sangicoccus sp., predator, biology

\footnotetext{
${ }^{1}$ PCA-Albay Research Center Banao, Guinobatan, Albay 4503 Philippines

E-mail address: johanacorense@yahoo.com

${ }^{2}$ Brooke's Point, Southern Palawan, Philippines

${ }^{3}$ PCA-Albay Research Center Banao, Guinobatan, Albay 4503, Philippines

E-mail address: marieimperial@yahoo.com

${ }^{4}$ Paulog, Ligao City, Philippines
} 


\section{Introduction}

Coconut is the top foreign currency earning agricultural commodity of the Philippines. As such, considerable resources have been invested in research studies on all aspects of increasing yield to maintain the country's reputation as one of the top coconut suppliers of the world. The widespread infestation of mealybugs in the island province of Palawan, Southern Philippines alarmed the authorities considering that $72 \%$ of the annual copra yield of the province is coming from these coconut palms (PCA-Palawan, 1996).

The pest now identified as Sangicoccus sp. nr. truncatispinus (Eriococcidae, Homoptera) is the first recorded mealybug species that seriously damaged the coconut palms in the Philippines. Its sedentary lifestyle and continuous manner of feeding cause chlorosis and the deposition of numerous extruded honeydew droplets on leaf surfaces. Thick sooty mold rapidly grows on the honeydew splattered on the leaf surfaces, thus, interfering with the palm's photosynthetic activity. Severely infested palms lose up to 53\% of total nut yield (PCA, 1996).

Studies funded by the Philippine government were conducted to gather biological and ecological information leading to the control of the pest. Investigations were concentrated on finding indigenous biological control agents, considering the perennial nature and the architecture of the coconut palm.

\section{Methodology}

Heavily colonized coconut palms were surveyed for the pest's natural enemies. Infested leaves were collected and caged for observation on emergence of parasitoids or predators. Insects gathered from trapping, sweeping and manual collection were sorted and identified. Techniques for rearing the predators in the laboratory were devised. Life history studies were undertaken as soon as laboratory rearing was successful.

The voracity of Dipha (Conobathra) aphidivora Meyrick was investigated. Newly laid eggs were individually placed in vials. Once hatched, the larvae were fed with unlimited number of pre-counted mealybugs. Daily consumption rate of each larva for each life stage was recorded.

\section{Results and discussion}

\section{Natural enemies of Sangicoccus sp.}

Field surveys and microscopic examination of mealybug infested leaf samples disclosed no insect pathogen but only one pupal parasitoid, Brachymeria sp. (Chalcididae: Hymenoptera) and 10 entomophagous predators (Neuroptera-four, Lepidoptera-two, Coleopterathree, and Hemiptera-one) were recorded preying on Sangicoccus sp. Among these, Dipha aphidivora was chosen for further studies because of ease in handling, rearing, and field collection and it displayed a voracious nature being able to consume the whole mealybug including the waxy secretions. It is an Asian species and a known predator of mealybugs and aphids in Japan, Papua New Guinea and Taiwan (Watson 1996). In Japan, D. aphidivora preyed on two species of aphids, the sugar cane woolly aphid Ceratovacuna lanigera Zehntner and Pseudoregma bambucicola (Takahashi) (Norio and Yutaka, 1988). Recent paper indicates that D. aphidivora was recorded earlier as a predator of sugarcane woolly aphid in Malaysia, China, India, Taiwan, Japan and the Philippines (Sunil Joshi and Viraktamath, 2004). The predator has been recorded under three names, Isauria aphidivora, Conobathra aphidivora and Cryptoblabes aphidivora. In the Philippines however, this species was reported from $C$. lanigera (Rueda and Calilung, 1974). The present record from coconut mealybug in the Philippines appears to be the first.

\section{Rearing of Dipha aphidivora}

Since this is the first record of occurrence on coconut mealybug in the Philippines, a rearing procedure was devised to enable bioecological studies to proceed. All stages of the larvae were collected from infested coconut leaves. These were confined in plastic rearing jars and fed with live mealybugs still attached to coconut leaves. Freshly collected mealybugs were supplied daily to these larvae. When the 
larvae metamorphosed into pupae, these were transferred to Petri plates for emergence. About six individuals of mixed sexes of newly emerged adults were transferred to each rearing jar and fed with fresh honey. The plastic jars were previously lined with wax paper on the sides and at the bottom for egg-laying. A wet cotton ball was placed on the bottom of the jar to maintain moisture. Wax paper laden with eggs was removed and replaced every two days and transferred to Petri plates for hatching. The succeeding stages were segregated by egg batch, placed in rearing jar and fed with mealybugs upon hatching. The procedure was repeated until a sufficient number of individual were produced for biological studies.

\section{Life history studies of Dipha aphidivora}

The female laid grainy oval, light brown eggs ( $5 \times 3 \mathrm{~mm}$, Figure 1) singly or in groups and the color darkened as the incubation period advanced. Predaceous larvae (Figure 2) passing through the four instars had smooth bodies and the color resembled the shade of the coconut leaflet. The second instar larva started to spin a web-like structure anchored on the leaves somewhat enclosing both the larva and the prey. It moved freely under the web searching for its prey. The third instar larva had the shortest duration of $2.83 \pm 0.72$ days while the first had the longest at $5.52 \pm 0.92$ days. The larvae are the only predaceous stage. The preys were consumed completely including the waxy secretions thereby cleaning the underside of leaves. Pupae $(9 \times 23$ $\mathrm{mm}$, Figure 3) were enclosed in a cylindrical, white silken cocoon anchored tightly on the underside of coconut leaves for $7.66 \pm 0.99$ days. The adult (Figure 4) that emerged from the pupa after $7.68 \pm 0.99$ days was gray brown with a body length of $61 \mathrm{~mm}$ and a wing span of $175 \mathrm{~mm}$. The antenna was filiform with a length of 3.0 $\mathrm{mm}$. The male to female ratio was $1: 1$. The mean duration of life cycle of $D$. aphidivora was $32.42 \pm 3.63$ days (Table 1). A hymenopterous parasite, Brachymeria sp. (Chalcididae: Hymenoptera) (Figure 5) was sometimes found attacking the larvae and pupae of $C$. aphidivora. It usually emerged from the predator's cocoon.

\section{Predation capacity of Dipha aphidivora}

The voracity of the four larval instars of D. aphidivora was investigated under laboratory conditions. The mean number of mealybugs consumed by the first instar larvae was $4.06 \pm 1.56$ and that of the second instar $20.67 \pm 20.11$. The third instar steadily increased its consumption to $54.83 \pm 34.89$ mealybugs while the last larval instar consumed the highest mean number of $137.41 \pm 56.85$ mealybugs. The mean total number of mealybugs consumed by an individual larva was 203.64 \pm 56.70 (Table 2). As for the prey stage preference, the first instar larva was observed to prey on some eggs but their exact consumption was not recorded since the eggs could not be pre-counted. The eggs are attached to the venter of the adult and cannot be dislodged for counting. Subsequent instars fed on nymphs, pupae and adults of mealybugs. All the larval instars had high preference for adults with eggs followed by the nymphs and adult without eggs. The least preferred stage was the pupa which might be due to its tough skin. Consumption steadily increased as the larva matured (Table 3 ). The actual consumption rate may have been higher since the eggs could have possibly hatched during the feeding period and were not included in the actual count.

In coconut production, pest management is cumbersome to farmers because of the large and tall canopy of the crop, making application of control measure difficult if not impossible. Moreover, the perennial nature of the palm (existing for more than 60 years) continuously provides shelter and food thus enhancing pest proliferation. The utilization, therefore, of biological control agents that are mobile and specific is a feasible alternative for effective pest management. Under laboratory conditions, D. aphidivora proved to be an efficient predator of the coconut mealybug. Its manner of feeding readily clears the leaf surfaces of the pest thereby resuming readily the photosynthetic activity of the palm. Dipha is reared to manage field populations of this aphid which severely infests the sugarcane. However, under Philippine conditions its field performance has 
Table 1. Life history of Dipha aphidivora under laboratory conditions

\begin{tabular}{|c|c|c|}
\hline \hline \multirow{2}{*}{ Developmental stage } & \multicolumn{2}{|c|}{ Duration (days) } \\
\cline { 2 - 3 } & Range & Mean \\
\hline Egg & $3-5$ & $4.64 \pm 0.70$ \\
\hline Larva & & \\
\hline 1st instar & $4-8$ & $5.52 \pm 0.92$ \\
\hline 2nd instar & $2-6$ & $3.40 \pm 0.91$ \\
\hline 3rd instar & $2-4$ & $2.83 \pm 0.72$ \\
\hline 4th instar & $2-5$ & $3.40 \pm 1.04$ \\
\hline Pupa & $7-11$ & $7.68 \pm 0.99$ \\
\hline Adult & $3-13$ & $6.83 \pm 2.30$ \\
\hline TOTAL & $26-37$ & $32.42 \pm 3.63$ \\
\hline \hline
\end{tabular}

Table 2. Predation response of Dipha aphidivora to Sangicoccus sp. under laboratory conditions

\begin{tabular}{|c|c|c|}
\hline \hline \multirow{2}{*}{ Larval stage } & \multicolumn{2}{|c|}{ Consumption rate (number of insects) } \\
\cline { 2 - 3 } & Range & Mean \\
\hline 1st instar & $2-7$ & $4.06 \pm 1.56$ \\
\hline 2nd Instar & $6-82$ & $20.67 \pm 20.11$ \\
\hline 3rd Instar & $17-173$ & $54.83 \pm 34.89$ \\
\hline 4th Instar & $56-260$ & $137.41 \pm 56.85$ \\
\hline TOTAL & $105-309$ & $203.64 \pm 56.70$ \\
\hline \hline
\end{tabular}

Table 3. Consumption of coconut mealybug by Dipha aphidivora larva under Laboratory conditions

\begin{tabular}{|l|c|c|c|c|}
\hline \hline \multirow{2}{*}{ Larval stage } & \multicolumn{4}{|c|}{ Average consumption of different stages of mealybugs } \\
\cline { 2 - 5 } & Nymph & Pupa & Adult only & Adult with eggs \\
\hline 1st instar & Not observed & 1 & 1.08 & 3.24 \\
\hline 2nd instar & 9.11 & 2.83 & 4.56 & 11.11 \\
\hline 3rd instar & 18.33 & 4.94 & 7.56 & 24.28 \\
\hline 4th instar & 49.23 & 10.23 & 23.23 & 54.71 \\
\hline \hline
\end{tabular}


Cord 2010, 26 (2)

Figure 1. Egg of Dipha aphidivopra

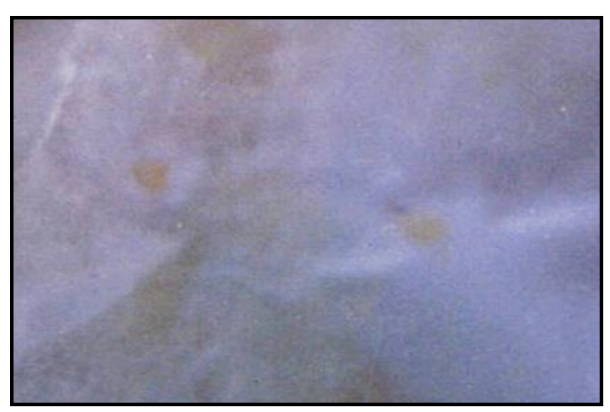

Figure 2. Larva of Dipha aphidivopra

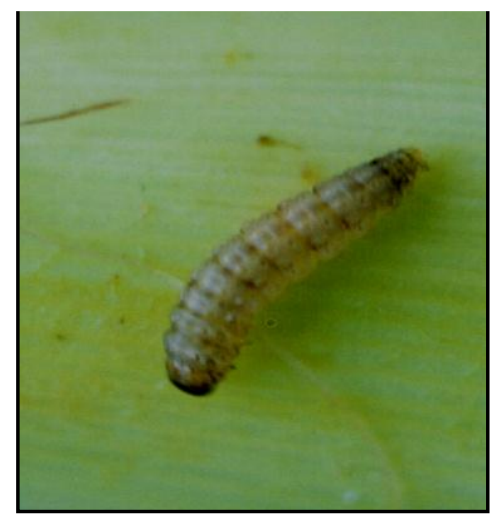

Figure 3. Pupa of Dipha aphidivopra

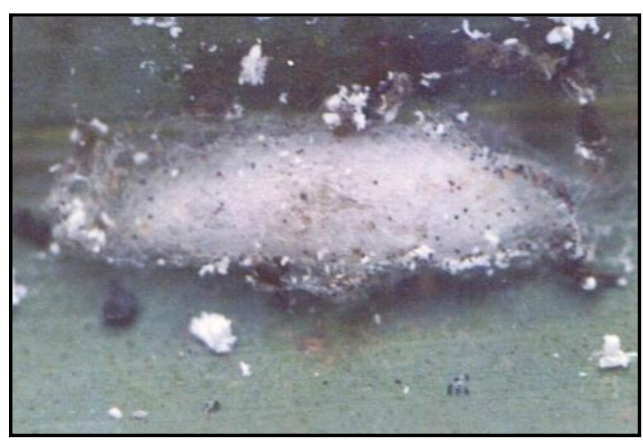

Figure 4. Adult of Dipha aphidivopra

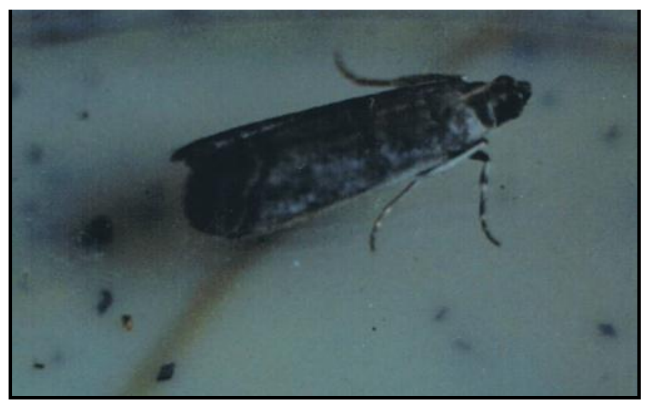


yet to be ascertained to explore fully its potential as a biological control agent. The appropriate life stages for field release, searching capacity of laboratory reared individuals and survival at low pest density are key factors that have to be investigated. Moreover, artificial diets need to be formulated to produce sufficient number of individuals at the right time if effective control is to be achieved.

\section{Acknowledgement}

The authors are grateful to the Department of Science and Technology-Philippine Council for Agriculture Resources Research and Development, and Philippine Coconut Authority for funding this research.

The insects were identified at the International Institute of Entomology, CABI, United Kingdom.

\section{References}

Norio, Arakaki and Yoshiyasu Yutaka. 1988. Notes on Biology, Taxonomy and Distribution of the aphidophagous pyralid, Dipha aphidivora (Meyrick) comb. nov. (Lepidoptera: Pyralidae). Applied Entom. Zool. 23(3): 234-244.

PCA-Palawan Annual Report 1996.

PCA. Annual Report 1996.

Rueda, L.M. and Calilung, V.J. 1974. Biological studies on the sugar-cane woolly aphid, Ceratovacuna lanigera Zehntner (Hemiptera: Aphidoidea: Pemphigidae) on five varieties of sugarcane. Philipp. Entomol. 3: 129147.

Sunil Joshi and Viraktamath, C.A. 2004. The sugarcane woolly aphid, Ceratovacuna lanigera Zehntner (Hemiptera: Aphididae): its biology, pest status and control. Curr. Sci. 87 (3):307-316. 
Cord 2008, 24 (1) 